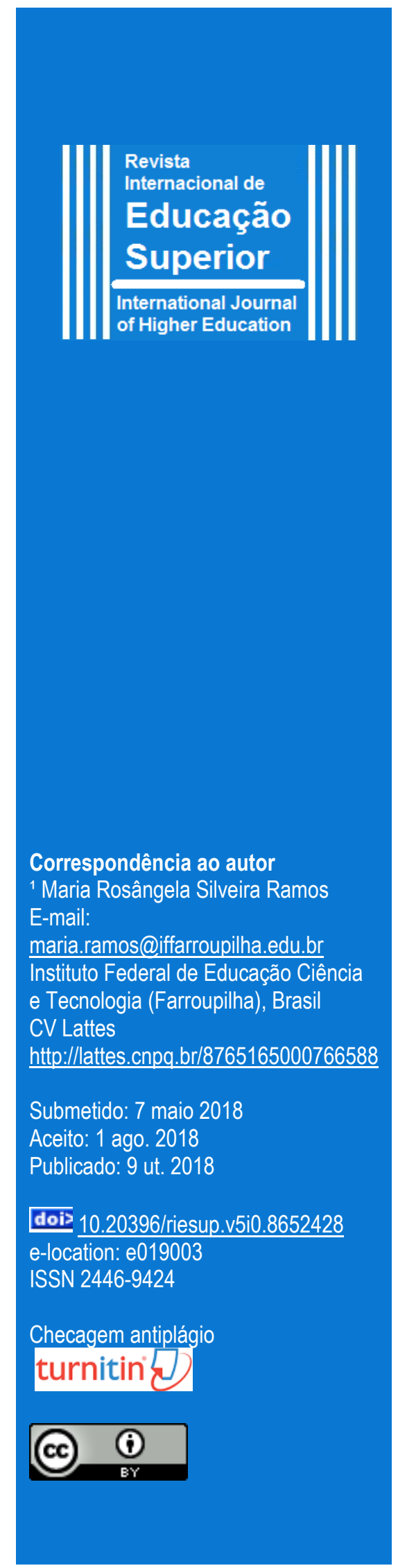

\title{
Auto(trans)formação permanente e desenvolvimento docente no contexto do PIBID
}

Maria Rosângela Silveira Ramos ${ }^{(\mathbb{D})}$, Celso $l$ go $\mathrm{Henz}^{2}(\mathbb{D})$, Dóris Pires Vargas Bolzan $^{3}$ (iD)

${ }^{1}$ Instituto Federal de Educação Ciência e Tecnologia (Farroupilha)

${ }^{2,3}$ Universidade Federal de Santa Maria

\section{RESUMO}

Este artigo resulta de uma pesquisa de doutorado concluída em 2017, que teve como objetivo compreender e analisar a realização e os desdobramentos formativos do Programa Institucional de Bolsa de Iniciação à Docência (PIBID), nos subprojetos de Química e Biologia em uma Instituição de Ensino Superior. As narrativas apresentadas são retiradas dos diálogos emergidos nos encontros presenciais, realizados em cada campus participante da pesquisa. Nesses encontros, utilizamos a metodologia dos Círculos Dialógicos Investigativo-formativos, inspirados nos Círculos de Cultura freireanos em aproximação com a pesquisa-formação. Os encontros possibilitaram a percepção de que os Círculos Dialógicos Investigativoformativos contribuem para a ação-reflexão-ação sobre as práxis educativas dos pibidianos e com a auto(trans)formação permanente tanto dos professores quanto dos bolsistas de iniciação, contribuindo com o desenvolvimento profissional docente.

\section{PALAVRAS-CHAVE}

Auto(trans)formação. Formação de professores. PIBID. Círculos dialógicos Investigativo-formativos. Desenvolvimento profissional docente. 


\title{
Permanent auto (trans) formation and teacher development in the context of PIBID
}

\begin{abstract}
This article is the result of a doctoral research completed in 2017, whose objective was to understand and analyze the achievement and the formative developments of the Institutional Program of Initiation to Teaching Scholarship (PIBID), in the subprojects of Chemistry and Biology in an Institution of Higher Education. The narratives presented are taken from the dialogues that emerged in face-to-face meetings, held at each participating campus of the research. In these meetings, we used the methodology of the Investigative-Formative Dialogical Circles, inspired by the Freirean Cultural Circles in approach to research-training. The meetings enabled the perception that the Investigative-Formative Dialogical Circles contribute to action-reflection-action on the educational praxis of the pibidians and to the permanent auto(trans)formation of both teachers and scholarship holders of initiation, contributing to professional development teacher.
\end{abstract}

\section{KEYWORDS}

Permanent Auto (trans). Teacher's formation. PIBID. Investigative-formative dialogical circles. Professional teacher development.

\section{Auto(trans)formación permanente y desarrollo docente en el contexto del PIBID}

\section{RESUMEN}

Este artículo resulta de una investigación de doctorado concluida en 2017, que tuvo como objetivo comprender y analizar la realización y los desdoblamientos formativos del Programa Institucional de Beca de Iniciación a la Docencia (PIBID), en los subproyectos de Química y Biología en una Institución de Educación Superior. Las narraciones presentadas son retiradas de los diálogos surgidos en los encuentros presenciales, realizados en cada campus participante de la investigación. En estos encuentros, utilizamos la metodología de los Círculos Dialógicos Investigativo-formativos, inspirados en los Círculos de Cultura freireanos en aproximación con la investigación-formación. Los encuentros posibilitaron la percepción de que los Círculos Dialógico Investigativoformativos contribuyen a la acción-reflexión-acción sobre las praxis educativas de los pibidianos y con la auto(trans)formación permanente tanto de los profesores y de los becarios de iniciación, contribuyendo con el desarrollo profesional docente.

\section{PALABRAS CLAVE}

Auto(trans)formación. Fromación permanente de profesores. PIBID. Círculos dialógicos investigativoformativos. Desarrollo profesional docente. 


\section{Introdução}

Este artigo resulta de uma pesquisa de doutorado ${ }^{1}$, a qual buscou compreender e analisar sobre as dinâmicas e possíveis desdobramentos de auto(trans)formação permanente com os professores e acadêmicos bolsistas do PIBID, nos subprojetos de Química e Biologia no Instituto Federal de Educação, Ciência e Tecnologia Farroupilha (IFFar), por meio dos Círculos Dialógicos Investigativo-formativos. A aproximação com o termo auto(trans)formação permanente origina-se nos estudos, pesquisas, participações e vivências dos integrantes do Grupo de Pesquisa Dialugus - Educação, Formação e Humanização com Paulo Freire. O Dialogus realiza diversas ações de pesquisa e extensão, com o objetivo de contribuir com processos de humanização e cidadania na educação e na sociedade, tendo como base o trabalho problematizador, dialógico e educativo-emancipatório do mesmo.

A auto(trans)formação permanente com professores é uma das temáticas que vem sendo consolidada como um dos movimentos de pesquisa nos Círculos Dialógicos Investigativo-formativos, propondo uma escuta sensível e o diálogo crítico-reflexivo acerca do próprio processo permanente (inicial e continuada) de auto(trans)formação (HENZ, 2015). A proposta político-epistemológica dos Círculos Dialógicos Investigativo-formativos possui suas raízes nos Círculos de Cultura de Paulo Freire, articulados com pressupostos da Pesquisa-formação de Josso (2004), com a valorização da dialogicidade, da escuta do outro, da construção das identidades, trabalhando com as trajetórias formativas pessoais e profissionais que geram (re)significação e auto(trans)formação permanente com professores.

As pesquisas realizadas pelo grupo Dialogus desde 2007, mostram que a auto(trans)formação permanente com docentes é mediada pela dialogicidade, como processos de ação-reflexão-ação, com a intenção de ações inovadoras e transformadoras, coletivas e ético-políticas, considerando como lócus, a práxis educativa escolar. Nesse sentido, a auto(trans)formação é uma (re)construção humana, histórica, social, na qual as vivências ao longo da vida, quer sejam pessoais ou profissionais, estão imbricadas, com vistas a uma práxis pedagógica humanizadora, emancipatória e libertadora.

Na sequência do texto apresentamos o caminho metodológico para a construção dos dados e provocar reflexões sobre: a maneira como as práticas educativas vêm contribuindo para a consolidação e fortalecimento da auto(trans)formação permanente com professores nas instituições de ensino, especialmente com o grupo de pibidianos.

\footnotetext{
${ }^{1}$ A tese de doutorado, concluída em 2017, apresentou como título "O PIBID DE QUÍMICA E BIOLOGIA DO IFFAR: ENTRE-LUGAR DE AUTO(TRANS)FORMAÇÃO PERMANENTE COM PROFESSORES”. DesSe modo, visando a ampliar as contribuições com as investigações sobre a validade formativa, social e educacional do programa PIBID, objetivou-se, com este trabalho, compreender como ocorre a dinâmica e possíveis desdobramentos de auto(trans)formação permanente com os professores e licenciandos bolsistas do Programa Institucional de Bolsas de Iniciação à Docência no Instituto Federal de Educação, Ciência e Tecnologia Farroupilha nos subprojetos de Química e Biologia, os quais estão vinculados aos cursos de licenciaturas da referida instituição.
} 


\section{Caminhos Metodológicos}

Para a construção metodológica deste estudo, foi determinante a realização de encontros dos Círculos Dialógicos Investigativo-formativos, de maneira que estes pudessem propiciar momentos em que todos os participantes tivessem a oportunidade do diálogo, da escuta, de dizer sua palavra, de ter uma atenção sensível, pois "somos seres em processos de (re)construção, inacabados na busca de ser mais ${ }^{2}$ ” (FREIRE, 1987, 2015a). A atenção sensível e o diálogo possibilitaram aos sujeitos, como seres inacabados em constante auto(trans)formação, a reflexão crítica e rigorosa sobre sua "práxis pedagógica" (HENZ, 2014a, p. 51).

Assim, considerando que os encontros pudessem possibilitar aos sujeitos sentirem-se participantes ativos da pesquisa, interlocutores (co)autores, fez-se necessário conhecer o contexto e não somente os fatos isolados e individualizados. Desse modo, todos os pibidianos têm o direito de falar, dialogar e dizer a sua palavra (FIORI, 1987). A pergunta não é específica da pesquisadora, ou apenas de um sujeito integrante do grupo, mas de todos os envolvidos nos encontros, estabelecendo relações de diálogo e, ao mesmo tempo, problematizadoras, sobre as quais cada um dos participantes pode exercer a palavra, ou melhor, possui a opção de "falar" ou "silenciar". Assim, "no processo da fala e da escuta a disciplina do silêncio a ser assumido com rigor e a seu tempo pelos sujeitos que falam e escutam é um sine qua da comunicação dialógica" (FREIRE, 2015a, p. 114).

Desse modo, utilizamos no conjunto do percurso metodológico, a abordagem qualitativa, por se considerar que esta se sucede das experiências e das vivências sentidas, percebidas e expressas. Enfim, das trajetórias formativas que os indivíduos carregam consigo ao longo das suas vivências, emergidas do seu mundo, do contexto histórico-social no qual estão inseridos. Segundo Gil (2009, p. 82), "graças à reconstrução histórica das situações vivenciadas pelos indivíduos, torna-se possível a compreensão do dinamismo dos processos sociais, que geralmente não se evidenciam em questionários e entrevistas”.

$\mathrm{Na}$ metodologia da pesquisa qualitativa, o pesquisador e os demais sujeitos estão inseridos no ambiente estudado, imersos nas temáticas de pesquisa, assim ela possibilita um melhor detalhamento das ações e uma flexibilidade nas atividades. Nesse sentido, na pesquisa qualitativa, os participantes são "reconhecidos como sujeitos que elaboram conhecimentos e produzem práticas adequadas para intervir no problema que identificam" (CHIZZOTTI, 2010, p. 83).

\footnotetext{
${ }^{2}$ A vocação para a humanização, segundo a proposta freiriana, é uma característica que se expressa na própria busca do ser mais através do qual o ser humano está em permanente procura, aventurando-se cuidadosamente no conhecimento de si mesmo e do mundo, além de lutar pela afirmação/conquista de sua liberdade (ZITKOSKI, 2010, p. 369).
} 
Portanto, a opção pela abordagem qualitativa (CHIZZOTTI, 2010, 2014), associada ao estudo de caso (GIL, 2009; YIN, 2015) e interligadas com a pesquisa-formação (JOSSO, 2004, 2010), de maneira dialógica entre os sujeitos participantes e a pesquisadora. Complementando as referidas abordagens, buscou-se trabalhar com a metodologia dos Círculos Dialógicos Investigativo-formativos (HENZ, 2014b), para a dinâmica dos encontros; a mesma inspira-se nos Círculos de Cultura de Paulo Freire em aproximação com a pesquisaformação de Josso (2004, 2010). A figura a seguir representa essa escolha.

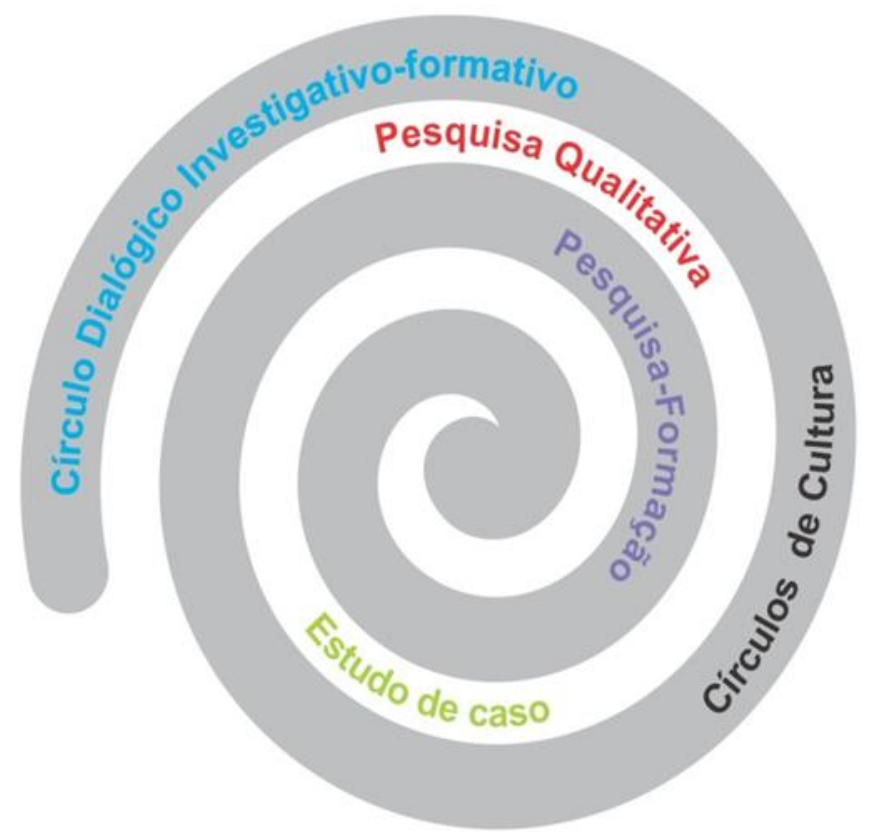

Figura 1. Representação do caminho metodológico escolhido para a pesquisa. Fonte: elaborado pela autora.

As relações metodológicas envolvendo o estudo de caso estão atrelados a um conjunto de dados, fatos, observações, anotações que propiciam ao planejamento das ações estar em constante (auto)transformação. Nesse viés, o estudo de caso analisa uma realidade sobre o objeto de estudo para, desse modo, "alcançar um conhecimento mais amplo sobre esse objeto, dissipando as dúvidas, esclarecendo questões pertinentes e, sobretudo, instruindo ações posteriores" (CHIZZOTTI, 2014, p. 135).

Nesse sentido, o estudo de caso busca a descoberta, mesmo que para a organização da dinâmica e das atividades desenvolvidas pelo grupo de sujeitos participantes, exista um pesquisador-líder em cada encontro. Denota-se que os sujeitos necessitam estar atentos às situações que podem emergir durante o estudo, especificamente durante os Círculos Dialógicos Investigativo-formativos. De acordo com Josso (2004), o pesquisador-líder não controla fenômenos, mas sim busca, com os sujeitos, [re]significar e auto(trans)formar suas atividades e ações durante a ação da pesquisa, em contextos nos quais a incerteza e o inacabamento sejam a "provocação e motivação" da (re)construção de novos conhecimentos, tanto para o professor, quanto para o pesquisador. Entendemos que esse tipo de pesquisa valoriza o conhecimento da experiência e o sujeito vai (re)construindo as suas próprias 
interpretações, vai se (auto)descobrindo como ser inserido e atuante na realidade, do contexto no qual está inserido, ou seja, como "seres humanos, como seres sociais, históricos, seres fazedores, transformadores, que não apenas sabem mas sabem que sabem" (FREIRE, 2011, p. 74-75).

Nessa perspectiva, os sujeitos participam efetivamente da pesquisa e são considerados coautores; busca-se, "através do diálogo-problematizador, proporcionar uma reflexão crítica sobre o ato educativo, com um coletivo de pessoas, educadores e/ou educandos, com base nas questões levantadas pelo grupo com relação à temática" (HENZ; FREITAS, 2015, p. 3), por meio da realização dos Círculos Dialógicos Investigativo-formativos. O Grupo Dialogus Educação, Formação e Humanização com Paulo Freire vêm concretizando como proposta epistemológico-política de pesquisa os Círculos Dialógicos Investigativo-formativos, com vistas a propor, pela trama de uma espiral proativa, os movimentos do olhar aguçado e da escuta sensível; do inacabamento; dos diálogos-problematizadores; da conscientização; e da auto(trans)formação, a partir das vivências e (re)significações da práxis educativa.

A constituição e desenvolvimento dos Círculos Dialógicos Investigativo-formativos possui suas origens nos Círculos de Cultura de Paulo Freire, devido à disposição dos sujeitos, na qual todos estão em torno do grupo de trabalho, com um interlocutor nos debates que não é, necessariamente, o pesquisador, mas um dos sujeitos participantes. Assim como nos Círculos de Cultura, os Círculos dialógicos "são modos próprios e novos, solidários, coletivos, de pensar" (BRANDÃO, 2013, p. 45), articulados com os pressupostos da Pesquisa-formação de Josso (2004, 2010).

Destacamos que a organização dos Círculos Dialógicos Investigativo-formativos não segue um roteiro, uma ordem ou um método "fechado", mas envolve a reflexão da prática educativa, a (re)construção e organização cooperativa, reconhecendo que "somente um trabalho coletivamente realizado pode chegar à construção de um saber" (JOSSO, 2010, p. 27) e possibilitar a ação-reflexão-ação das atividades e ações desenvolvidas pelos sujeitos com vistas a auto(trans)formação docente.

\section{A Auto(trans)Formação com Professores}

A formação de professores é um assunto vastamente discutido e refletido por muitos autores, também por Freire $(1987,2015 a)$. A constituição a respeito desse tema procedeu, ao mesmo tempo, do entusiasmo criador e inspirador da sua prática pedagógica, com os diálogos que manteve com docentes nas suas andarilhagens pelo mundo e pelo Brasil, e de suas convicções sobre a importância da formação na ação de ensinar e aprender.

Nos escritos freireanos, vai sendo elaborada e (re)construída a concepção do saber fazer (FREIRE, 1987, 2015a), evidenciando os fundamentos políticos, filosóficos e antropológicos de sua proposta, estabelecendo relações com a concepção da práxis docente, relacionando-os ao ensinar e aprender numa interação com a formação dos professores. Ou

\begin{tabular}{l|l|l|l|l|l|}
\hline CC Rev. Inter. Educ. Sup. & Campinas, SP & v.5 & $1-21$ & e019003 & 2019 \\
\hline
\end{tabular}


seja, "quem ensina aprende ao ensinar e quem aprende ensina ao aprender. Quem ensina, ensina alguma coisa a alguém" (FREIRE, 2015a, p. 25).

A formação permanente, na perspectiva de Freire (1987, 2015a) tem como característica principal o trabalho coletivo, em que o diálogo se instaura como componente e dispositivo para estabelecer as relações entre os sujeitos e a problematização, como constituição processual crítica de saberes e quefazeres pela ação-reflexão-ação. No entanto, faz-se necessário todos reconhecerem, assumirem e desenvolverem essa postura dialógica, pois "através do diálogo podemos olhar o mundo e a nossa existência em sociedade como processo, algo em construção, como realidade inacabada e em constante transformação" (ZITKOSKI, 2010, p. 117).

Nesse sentido de realidade inacabada em (trans)formação, a formação permanente pressupõe que os pibidianos (formador e formando) entendam-se como sujeitos inconclusos em constante evolução e aperfeiçoamento, sendo essa uma necessidade humana que (re)conduz o indivíduo de maneira curiosa e crítica ao buscar o conhecimento de si e do mundo. Visualiza-se, assim, a necessidade de programas de desenvolvimento profissional docente, articulados às instituições de ensino superior e escolas de educação básica, para que se possa desenvolver um trabalho cooperativo, reconstruindo os espaços acadêmicos e escolares de uma maneira direcionada, envolta no contexto histórico e cultural dos sujeitos em formação, sejam licenciandos ou professores já no exercício da docência. Desse modo, faz-se necessário (re)pensar e fomentar estratégias e entre-lugares para que a formação ocorra em articulação com o exercício da profissão, o que se entende como permanentes processos de "auto(trans)formação" (HENZ, 2014, 2015).

No entanto, é imprescindível pensar em uma auto(trans)formação que esteja ao alcance de todos e digna de melhoria na qualidade de ensino para a educação em geral, e, em especial, às classes populares. Logo, formação docente, segundo Garcia (1999), pode ser compreendida como processos "[...] que possibilitam aos professores adquirir ou aperfeiçoar seus conhecimentos, habilidades, disposições, para exercer sua atividade docente, de modo a melhorar a qualidade da educação que seus alunos recebem" (p. 26). Esse enfoque que fundamenta a "formação docente" tem sido aceito por muitos estudiosos da área, que consideram de grande importância a atenção nos processos de preparação, profissionalização e socialização dos professores, tendo em vista a aprendizagem do estudante.

A formação de professores, reconhecida como auto(trans)formação ligada à profissão, leva ao desenvolvimento de uma "nova" configuração; ou seja, a profissionalidade docente, estimulando a emergência de uma cultura profissional no seio do professorado e de uma cultura organizacional no seio das escolas (NÓVOA, 1997, p. 24). Provoca, assim, na formação, o desenvolvimento profissional dos professores, no quadro de uma autonomia contextualizada da profissão docente (NÓVOA, 1997, p. 27). 
Dessa forma, associar a auto(trans)formação permanente ao desenvolvimento profissional docente, no contexto em que os sujeitos estão inseridos, importa valorizar concepções e práticas de formação que promovam a preparação de professores reflexivos, que assumam a responsabilidade do seu próprio desenvolvimento profissional e que participem como protagonistas na implementação das políticas educacionais (NÓVOA, 1997, p. 27).

Isso faz surgir à percepção de que o desenvolvimento tanto pessoal quanto profissional (NÓVOA, 1997) do educador é inacabado e permanente, acontece no decorrer dos diferentes períodos da sua história, ou melhor, desde a formação inicial, prolongando-se ao decorrer da sua profissionalização. Entretanto, é importante que o professor deseje modificar suas ações, entendendo serem necessárias mudanças na cultura escolar, que incluam a consolidação de práticas educativas com inovação e uma gestão democrática participante nas atividades e nas ações, com esperança de melhorar o ensino e a educação. Dito de outra forma, desenvolver-se pessoal e profissionalmente requer a disposição e abertura para o (re)encontro consigo mesmo, com suas práxis, o que sempre se dá também pelo encontro com os outros, pelo diálogo crítico-reflexivo pelo qual se vão vislumbrando novos olhares, novas possibilidades e novas ações tanto no cotidiano social como pedagógico.

Desse modo, a auto(trans)formação docente e o desenvolvimento profissional podem contribuir com o papel do educador e da educadora, entre os quais está o de cuidar para que a esperança não se desvie e não se perca, caindo na desgraça ou no desespero (STRECK, 2010, p. 161), ou seja, a esperança, como necessidade ontológica, precisa da prática para se tornar concretude histórica (FREIRE, 2014, p. 15).

Ademais, o desenvolvimento profissional docente pressupõe um enfoque de formação dos professores que valoriza seu caráter contextual, organizativo e orientado para o trabalho (GARCIA, 1999, p. 154). O desenvolvimento profissional docente implica uma valorização dos aspectos contextuais, organizativos e guiados para a transformação, como um princípio de indagação-reflexão. Ou seja, "a indagação reflexiva analisa as causas e as consequências da conduta docente, superando os limites didáticos e da própria aula" (GARCIA, 1992, p. 55).

Ao se pensar em propostas que venham ao encontro de uma perspectiva de auto(trans)formação docente, visualizou-se que, no contexto educacional, ainda se está aquém de como organizar e fomentar ações nesse sentido. Encontrou-se uma conjuntura de acontecimentos em que entrava todo o planejamento, que envolve desde a parte organizativa e administrativa da escola até as condições de trabalho dos próprios professores, entre elas: jornada de trabalho, horário compatível para a realização de atividades formativas, valorização salarial e uma política educacional que possibilite e fomente o custeio para a realização periódica e sistematicamente dos encontros auto(trans)formativos (IMBERNÓN, 2009, 2010, 2011).

Nesse entremeio, a auto(trans)formação docente não deve ser vista de maneira isolada, e precisa aproximar-se da realidade escolar, de suas problemáticas, possibilitando que se 
trabalhe articuladamente com a própria comunidade e com as Instituições de Ensino Superior, permitindo, por meio de programas e de políticas formativas, que esse processo aconteça no próprio ambiente de trabalho.

A abrangência do termo "formação docente" não está restrita à formação acadêmica, ou seja, como discente de um Curso de Licenciatura. Acredita-se que o diálogo entre profissionais já atuantes nas instituições educativas e entre os acadêmicos em formação nos cursos de licenciatura provoca e possibilita maiores discussões nos processos de auto(trans)formação permanente com professores já no exercício da docência, buscando aprofundamento e melhoria do desenvolvimento da profissão.

\section{O Desenvolvimento Profissional Docente}

Considerar que o desenvolvimento profissional docente é uma tarefa em que os docentes são desafiados ao compromisso individual, coletivo e institucional, em prol de refletir e (re)inventar ações que possibilitem uma educação que se coloque a serviço do empoderamento de cada estudante e professor na sua auto(trans)formação pessoal, profissional e cidadã. Sob essa perspectiva, o desenvolvimento profissional sugere reconhecer que o processo envolvido é permanente, abrangendo fatores históricos, sociais, culturais, institucionais e econômicos, considerando que esse movimento formativo é permanente e permeia a profissão docente que vem se constituindo no antes, durante e no depois da formação inicial.

A expressão desenvolvimento profissional docente tem assumido distintos significados, sendo usada em diversos contextos e em diferentes tipos de práticas. Apropriamo-nos, aqui, da síntese do termo construída por Marcelo (2009, p. 7).

É uma construção do eu profissional, que evolui ao longo das suas carreiras. Que pode ser influenciado pela escola, pelas reformas e contextos políticos, e que integra o compromisso pessoal, a disponibilidade para aprender a ensinar, as crenças, os valores, o conhecimento sobre as matérias que ensinam e como as ensinam, as experiências passadas, assim como a própria vulnerabilidade profissional.

O desenvolvimento profissional docente é um processo evolutivo, em que as vivências pessoais do professor estão interligadas com as experiências profissionais, e também são indissociáveis da própria instituição, do seu currículo e das suas particularidades. Necessita ser um processo interativo, dinâmico, ininterrupto, sem finitude, o qual abranja tanto os aspectos conceituais quanto os comportamentais (GAMA, 2007).

As trajetórias formativas não são finitas, mas inacabados processos de auto(trans)formação. Dessa forma, o desenvolvimento profissional está associado à identidade pessoal de cada docente, à formação inicial e continuada no decorrer do exercício 
da profissionalização e às interações humanas que são estabelecidas e mediadas nos espaços escolares. Desse modo,

acreditamos que o ponto de partida para o avanço no campo do desenvolvimento profissional precisa contemplar os referenciais que os professores têm de si mesmos e de suas trajetórias formativas, ou seja, como vêm constituindo sua professoralidade (ISAIA; BOLZAN, 2009, p. 167).

Nesse sentido, o desenvolvimento profissional docente encontra-se entrelaçado à trajetória formativa e às experiências de vida e profissional, as quais incentivam os docentes a refletir sobre suas práxis, por meio da interação e da mediação intersubjetiva com a dos demais sujeitos. Esse movimento cooperativo é necessário para que os professores "possam abraçar o desafio dos novos papéis de ensino e encará-los como desafios em vez de pesos a carregar" (DAY, 2001, p. 308). Os efeitos desse envolvimento reflexivo e investigativo nos processos auto(trans)formativos incidem o uso das histórias e das narrações que envolvem a formação, podendo potencializar a (re)elaboração e a (re)significação de formas de pensar, ideias e vivências, oportunizando (re)construções na prática educativa. Tudo isso passa necessariamente por práticas auto e intersubjetivas que se viabilizam pelo diálogo críticoproblematizador, na dialética ação-reflexão-ação.

O desenvolvimento profissional docente e "formação entrelaçam-se em um intricado processo, a partir do qual o docente vai se construindo pouco a pouco" (ISAIA, 2006, p. 375). Desse modo, é compreendido como uma ação individual e coletiva que ultrapassa a formação inicial e continuada, a qual ocorre em contextos concretos, interligando a profissionalização, a profissão docente, os conhecimentos da carreira e a trajetória formativa, (re)descobrindo expressivos subsídios e aportes teórico-práticos na constituição da formação didáticopedagógica do professor.

O professor constitui-se como sujeito do processo em auto(trans)formação permanente. Portanto, seu desenvolvimento profissional é constante, espiralizado, inacabado e permeia toda a sua carreira docente. Abrange muito mais do que a participação em cursos, considerando também o lócus escolar como o ambiente para propiciar a formação de cada professor, também nas dimensões pessoais e sociais. Para isso, assume uma postura ética e crítica, tornando-se "capaz de apreender o caráter contraditório da prática pedagógica, articulando um discurso marcado pela linguagem da crítica e da possibilidade" (SANTOS, 1991, p. 325).

Nesse sentido, o reconhecimento da linguagem crítica perpassa a ideia de tomada de consciência, para adentrar nos movimentos de escutar, distanciar-se, dialogar, admirar, refletir sobre, ou seja, realizar a "reflexão crítica sobre os condicionamentos que o contexto cultural tem sobre nós, sobre nossa maneira de agir, sobre nossos valores" (FREIRE, 2013, p. 110). Dessa forma, o sujeito vai além da reflexão, passa a repensar seu trabalho tanto nas ações individuais como nas coletivas, bem como sobre os métodos usados no contexto históricocultural-social; para tanto, lança-se em permanentes, por vezes conflituosos, processos de 
ação-reflexão-ação, com vistas a contribuir com uma educação e uma sociedade mais justa e humanizadora.

O desenvolvimento profissional dos docentes efetiva-se em conjunto com a formação docente, sendo o "momento fundamental o da reflexão crítica sobre a prática" (FREIRE, 2015b, p. 40). Essa reflexão crítica dá-se na possibilidade de troca de experiências, de saberes e de conhecimentos entre os pares, nos momentos dialógico-problematizadores que desencadeiam a auto(trans)formação permanente, bem como nos processos de ensinaraprender com os estudantes; no caso desta tese, entre os formadores e os licenciandos. A reflexão crítica na/sobre a prática pedagógica voltada para o docente e seu desenvolvimento profissional torna-se uma exigência da relação entre teoria e prática, mais especificamente ainda para os participantes do PIBID.

Nesse contexto, os Círculos Dialógicos Investigativo-formativos contribuíram significativamente com os processos de diálogo-reflexivo entre os professores e acadêmicos sobre seus contextos formativos e seu desenvolvimento profissional. Percebe-se isso nas narrativas de sujeitos participantes da pesquisa de doutorado:

[Os círculos] possibilitou repensar, refletir sobre a prática docente ao longo da trajetória profissional anterior e sobre as mudanças de postura profissional, planejamento, ênfase e escolha de conteúdos e relações inter e intraespecíficas com a comunidade escolar futura. $O$ movimento de ensino-aprendizagem, a ação reflexão-ação foi constante, tanto quanto ao desvelar minha experiência docente, quanto ao aprender novos conhecimentos, com o grupo do PIBID. Houve uma troca constante e crescente de aprendizagens (PROFESSORA TRÊS MARIAS).

Os Círculos Dialógicos nos conduziram de maneira natural a uma auto(trans)formação, pois foi um momento onde analisamos toda a nossa trajetória e podemos perceber o quanto mudamos neste tempo de participação no PIBID (LICENCIANDO LÍRIO).

[Os Círculos] tornou o assunto mais fácil de ser abordado, foi possível uma participação coletiva e essas discussões serviram para repensar a formação e, principalmente, a ação docente (PROFESSORA ROO).

[os encontros] foram muito bons, não conhecia esse método e está me fazendo repensar minhas maneiras e formas de trabalhar frente ao aluno (PROFESSORA IVETE).

Os registros feitos pelas professoras participantes dos subprojetos de Química e Biologia do IFFar demonstram a importância e a necessidade de envolvimento e reflexão sobre a práxis pedagógica como uma atividade permanente e auto(trans)formadora. Dialogando nos encontros do grupo, coordenadores, professores de Educação básica e licenciandos tiveram a oportunidade de repensar suas trajetórias, trilhando caminhos em busca de novas formas de sentir/pensar/agir ${ }^{3}$ (HENZ, 2003), na sua profissão e ação docente.

\footnotetext{
${ }^{3}$ As dinâmicas de auto(trans)formação permanente docente, constituídas dialogicamente, possibilitam aos sujeitos, no seu inacabamento, sentir/pensar/agir (HENZ, 2003), para que possam "transformar a si mesmos e a realidade vigente, sempre pelo diálogo e intersubjetividade de uns com os outros" (HENZ, 2015a, p. 21).
} 
Essas relações que se originam de uma ação dialética são recíprocas e de justaposição (FREIRE, 2015a).

Na construção da identidade docente, o professor pode valorizar suas experiências formativas vividas ao longo de seu desenvolvimento profissional, no processo pelo qual pode revivê-la por meio da memória ressignificante e reconstrutiva, conseguindo, desse modo, convertê-las em aprendizagens experienciais, na busca de melhor qualidade para seu trabalho. A seguir, apresentaremos alguns relatos sobre as vivências que o PIBID oportuniza aos integrantes em auto(trans)formação permanente, colaborando, assim, com o seu desenvolvimento profissional docente.

\section{As Vivências e Contribuições do Pibid para a Auto(Trans)Formação}

O programa PIBID propõe-se à aproximação da relação entre a formação inicial nas IES - especificamente com os cursos de licenciatura - e a prática profissional dos professores em exercício na docência nas escolas de Educação Básica, compartilhando e agregando informações e conhecimentos com os bolsistas de iniciação à docência, os quais também podem colaborar para o desenvolvimento de sua identidade profissional docente.

A possibilidade de aproximação com a escola, para os pibidianos, antes dos estágios, propicia um novo "olhar" sobre a ação do ensinar e aprender, organizando e construindo inovações, metodologias investigativas e reflexivas para a melhoria da qualidade do ensino na educação básica e como espaço de auto(trans)formação permanente com professores. Dessa forma, o PIBID se constitui em um espaço-tempo rico de formação para todos. A seguir, trazemos as narrativas de dois sujeitos acadêmicos que integram o PIBID do IFFar. Eles afirmam:

\footnotetext{
A minha percepção é que quando cheguei no PIBID estava no terceiro semestre, ai pensei: "meu Deus, será que quero mesmo ser professora?". O PIBID te trás essa noção, te mostra a realidade das escolas, antes do estágio e você aprende a planejar uma aula, aprende a conviver em grupo. Então acho que ele mostra realmente a realidade do professor. É muito válido antes do estágio, porque daí vai dar a certeza se realmente é o que se quer [ser professor]. Porque ali há as vivências, daí dá uma boa conclusão se é isso que se quer para a vida [profissional] (LICENCIANDA ISIS).
}

O PIBID é um programa de fundamental importância, não só pelo processo de empoderamento, mas de descoberta da docência, porque ele mexe com a dinâmica da escola. [...] O PIBID tem um peso muito considerável nessa questão do empoderamento, da descoberta de "ser professor". Então costumo dizer que o PIBID é uma revolução silenciosa! (PROFESSOR PAULO).

Com base nas narrativas dos sujeitos, entende-se que o programa tem contribuído significativamente com a formação teórico-prática dos licenciandos, permitindo a eles planejarem e buscarem novos recursos, a fim de (re)organizarem as suas atividades. A integração da IES com a escola possibilita uma vivência mais "efetiva" do bolsista de 
iniciação à docência no/do ambiente escolar, potencializando aprendizagens, modificando visões e contribuindo para o desenvolvimento profissional docente de formandos e de formadores.

Corroborando, essa ênfase da inserção dos bolsistas de iniciação à docência, destacando a importância e o comprometimento da formação inicial ser "estabelecida dentro da profissão docente" também se encontra assinalada por Nóvoa $(2009$, p. 11) quando este destaca a contribuição dos professores em exercício, valoriza a coparticipação, as tarefas e as ações planejadas e desenvolvidas em equipe, propiciando um aprendizado na coletividade da profissão docente. O desenvolvimento das atividades dos subprojetos no coletivo permite aos pibidianos, formandos e formadores, compreenderem que a escola de Educação Básica é lócus das vivências e experiências da formação inicial e do desenvolvimento profissional docente, permanentemente.

Nesse viés, entende-se que a auto(trans)formação de novos profissionais da educação exige abertura ao outro, valorização do licenciando e, principalmente, "gostar do que se faz", ser competente, ter "afinidade" com a profissão docente. Ademais, além desse engajamento com a docência nas suas múltiplas e interligadas dimensões, faz-se necessário encontrar-se comprometido "não apenas na consciência da realidade, mas também o engajamento na luta para transformá-la" (FREITAS, 2010, p. 88).

Daí a importância de a escola ser o locus a propiciar sistematicamente encontros dialógico-reflexivos entre os professores, e também com os licenciandos em formação inicial; neles, na cooperação intersubjetiva, cada um pode se descobrir e assumir como sujeito autor da sua própria formação. Freire (2015 b) afirma que ninguém nasce "marcado para ser professor" (p. 102), ou seja, a identidade profissional docente vai se constituindo com as próprias práticas e com as dos demais sujeitos, sejam eles colegas ou estudantes. Assim, a formação docente é uma ação-refleção-ação complexa e permanente, que não ocorre no isolamento e no dogmatismo, necessitando persistir durante toda a trajetória formativa do professor, colocando-se como necessidade individual e coletiva.

Nessas relações e inter-relações com os outros e com o mundo, "a troca de conhecimento que acontece entre todos", como disse a licencianda Nicoli, possibilita a auto(trans)formação permanente e o desenvolvimento de uma consciência de inacabamento, em que (re)aprender criticamente leva ao exercício de uma ação criadora e (trans)formadora, de si, dos outros e dos contextos em que se está inserido. Também a professora Violeta, enfatizou que os momentos de formação permanente são imprescindíveis, e que o PIBID é um exemplo disso:

O PIBID é um espaço de formação, porque, na escola, não se tem uma formação específica na área e nem na disciplina. A gente tem informações gerais, então o PIBID faz repensar, estudar, faz buscar outras formas de metodologias. É diferente. Contribui muito com leituras, escritas, artigos. Então, aqui [no PIBID] se tem tempo para se dedicar a isso, na escola não se tem esse tempo, na escola o tempo que se está é sala de aula e, fora disso, não se tem esse tempo pra fazer uma 
metodologia diferente, para produzir algo diferente. Então, é um ganho, não tem comparação. Nós professores do PIBID e professores sem o PIBID!

Denota-se que Violeta considera a necessidade de momentos diferenciados de formação, em que todos - professores, licenciandos e estudantes -, tenham a oportunidade de refletir mais profundamente sobre as ações de aprendizagem que são e/ou podem ser realizadas na escola. A narrativa da coautora demonstra que o PIBID é esse espaço, esse "entre-lugar" de vivências e culturas diferentes; um espaço-tempo reconhecido e assumido, não desordenadamente, mas a partir dos significados de quem o ocupa, oportunizando o (re)encontro entre discente e docente, envolto pelas experiências e aprendizagens (re)construídas tanto na formação acadêmica quanto ao longo da docência, condicionadas também pelas características de cada contexto sócio-político-econômico-cultural.

Nessa perspectiva, o PIBID desencadeia e desenvolve uma auto(trans)formação baseada no diálogo crítico-reflexivo, pela "compreensão compartilhada pelos participantes, sobre as tarefas profissionais e os meios para melhorá-los” (IMBERNÓN, 2011, p. 87). A auto(trans)formação, compartilhada no reconhecimento de que os outros também são sujeitos co-autores da auto(trans)formação de cada participante, interformativa e cooperativamemente, o que também desafia estar aberto às "novas" situações de ensinaraprender, às novas metodologias e estudos, para que se possa compreender e atuar de acordo com as finalidades esperadas e planejadas coletivamente em cada contexto.

As interações entre formandos e formadores, na problematização e nas discussões, contribuíram para as narrativas e os diálogos de ação-reflexão-ação nos encontros dos círculos, mobilizando os sujeitos para a conscientização e o comprometimento com os diferentes, talvez novos, quefazeres educativos. A professora Lírio declara: "os círculos dialógicos, os debates e reflexões no grupo nos fazem, sim, refletir e isso nos leva à auto(trans)formação e deveria acontecer nos grupos mais vezes".

Evidencia-se que os encontros dos Círculos Dialógicos Investigativo-formativos possibilitaram um espaço de convivência e compartilhamento de ideias, de dialogicidade entre os sujeitos, ao mesmo tempo em que provocaram a concretização de ações auto(trans)formadoras. Essa afirmativa é confirmada pelos sujeitos coautores durante o quarto encontro:

Por meio dos encontros, consegui refletir sobre a realidade das escolas, bem como sobre a docência. Além disso, aprendi com os demais colegas e compartilhei experiências. Tenho certeza que um pouco da prática docente deverei aos encontros que contribuíram em diversos fatores, como na minha formação inicial e humana (LICENCIANDA NICOLI).

[...] qualquer intervenção que venha discutir ou abordar sobre questões relacionadas à docência sempre contribui muito, trazendo por meio destas experiências muito válidas que visam melhorar a nossa formação e futuramente em nossa prática docente (LICENCIANDA SOFIA).

[...] esta forma diferenciada contribuiu muito para a minha carreira como professora. Tenho certeza que ao entrar em uma sala de aula aplicarei o círculo 
dialógico, pois com ele além do aprendizado do aluno, o professor também aprenderá e conhecerá seus alunos (LICENCIANDA TAILANA).

A centralidade dos encontros dos Círculos Dialógicos é a dialogicidade, como prática de reconhecimento para com cada participante coautor, pela escuta sensível e o "dizer a sua palavra" (FIORI, 1987) voltada a uma prática pedagógica emancipatória, coletiva, problematizadora, em que os participantes se percebam como sujeitos do seu sentir/pensar/agir, discutindo sobre "sua própria visão do mundo, manifestada implícita ou explicitamente, nas suas sugestões e nas de seus companheiros” (FREIRE, 1987. p. 69). Assim também, dialeticamente, conscientizam-se das responsabilidades e possibilidades de agir em seu contexto social, originando as (trans)formações indispensáveis para a sua permanente (re)construção e humanização.

A reflexão crítica, na auto(trans)formação permanente com professores, compreende o comprometimento com a transformação de si e da realidade, pela práxis que é a relação dialética entre ação-reflexão-ação, na qual o agir e o pensar estão conectados e interligados, imbuídos de criticidade. Como destaca Freire (1979), se o sujeito possui a habilidade de agir, atuar, modificar a realidade, possui também capacidade de refletir, o que o faz um ser da práxis.

Assumindo esse entendimento do que fazer e "ser da práxis", entende-se que a formação permanente valoriza a coletividade e, portanto, é dialógica e instiga a participação de todos nas ações auto(trans)formativas inter-cooperativas. A narrativa da licencianda Iana revela que "a formação do professor é permanente, nesse sentido, várias metodologias e práticas foram discutidas e avaliadas nos encontros e também nas reflexões sobre as práticas educativas". Ou seja, os diálogos problematizadores possibilitaram a tomada de consciência, e a projeção de ações sobre o que foi refletido e, consequentemente, retroalimentando a processualidade da auto(trans)formação de/com todos.

O PIBID e os Círculos Dialógicos Investigativo-formativos mostram que, na formação permanente de professores, a reflexão crítica e o diálogo são essenciais para os processos de auto(trans)formação, primando a escola como lócus de formação, de trocas, de aprendizagens entre formandos e formadores, como se pode observar nas narrativas a seguir:

A prática de compartilhar nossas experiências e angústias aparece com muita
frequência nos Círculos Dialógicos. As ideias expostas por todos servem para
repensar a prática docente, pois é necessário atualizar-se e adaptar o trabalho
dentro da sala de aula para as vivências do aluno, procurando melhorar para
proporcionar uma melhor aprendizagem (LICENCIANDA LARA).

Acredito que tenha sido uma experiência muito enriquecedora, pois oportunizou momentos para a reflexão da própria prática e de diálogo acerca da mesma. Além de oportunizar um momento para ouvir experiências (trocas) entre os colegas (LICENCIANDA SOFIA).

As vivências e as participações nos encontros de auto(trans)formação dos subprojetos do PIBID constituíram-se em um primoroso entre-lugar de aprendizagens e de troca de 
experiências. Além disso, foram mobilizadoras de discussões sobre a necessidade de aproximar os conhecimentos com a realidade dos estudantes, partindo de suas vivências e de seu contexto.

Nos registros dos coautores, percebe-se que as trocas e as interações mediadas e estabelecidas pelos sujeitos oportunizaram refletir sobre suas ações e suas atividades no PIBID e na escola de Educação Básica. As temáticas geradoras emergiram do grupo, não foram impostas, mas indicadas e escolhidas pelos integrantes. Esses movimentos nos Círculos Dialógicos Investigativo-formativos são realizados com uma "circularidade em espiral ascendente proativa que se movimenta dentro da condição ontológica do inacabamento humano em busca do ser mais, o que só é possível pelo diálogo com os outros e com o mundo" (HENZ, 2015, p. 20).

Desse modo, além das contribuições com as práxis docentes, os círculos estabeleceram as relações entre formandos e formadores como ato amoroso e rigoroso, no convívio, na compreensão de que todos têm o direito a falar, a dizer sua palavra. Assim, como expressa a professora Martina, "com essa forma de trabalho, pode-se visualizar que o professor não é e nem precisa ser o dono da verdade absoluta. É possível haver aprendizagem no ato de ouvir e dar espaço para que todos falem". Deixar o outro expressar sua opinião e ouvi-lo atentamente é uma ação que permite a ação-reflexão-ação, com vistas ao ser mais de todos, para a compreensão do outro, bem como para que haja confiança, reciprocidade e o respeito nos processos de ensinar-aprender.

Entender a auto(trans)formação docente, partindo da importância da reflexão sobre a prática educativa, ou seja, "pensando criticamente a prática de hoje ou de ontem, que se pode melhorar a próxima prática” (FREIRE, 2015b, p. 40), requer a (re)organização dos espaços educativos, assim como de toda a conjuntura organizativa que permeia as escolas.

Nessa dimensão, a auto(trans)formação permanente possibilita a ação-reflexão-ação cooperativa, contribuindo não só com a melhoria da qualidade da práxis dos professores que já atuam na escola de educação básica, como também com a formação inicial dos licenciandos; torna-se um educar(-se) uns com os outros, preparando os futuros professores para que já cheguem na escola abertos ao diálogo e à construção democrática dos processos de ensino-aprendizagem, ainda que com muitas incertezas. Ademais, é necessário um conjunto de peculiaridades referentes à formação permanente para um avanço no processo auto(trans)formativo, destacando-se, entre elas, o desafio de partir dos projetos das escolas, para que grupo de professores decida qual a formação mais pertinente e coerente a se levar adiante nesse lócus, com vistas à colocação em prática e a avaliação do projeto (IMBERNÓN, 2009).

Nesse sentido, a reflexão sobre a prática pedagógica necessita estar inserida no contexto escolar, de maneira contextualizada com a realidade e interligada e ser debatida, refletida e decodificada entre os professores e os estudantes, os quais fazem parte da 
instituição. Assim, visualiza-se a possibilidade de uma auto(trans)formação permanente reflexiva e proativa, ou seja, de

[...] formar um professor como um profissional prático-reflexivo que se defronta com situação de incerteza, contextualizadas e únicas, que recorre à investigação como uma forma de decidir e de intervir praticamente em tais situações, que faz emergir novos discursos teóricos e concepções alternativas de formação (IMBERNÓN, 2011, p. 41).

A formação de um professor prático-reflexivo possibilita (re)pensar as teorias, as ações, as atitudes, realizando um processo dialético e constante de ação-reflexão-ação pessoal e profissional que venha a redirecionar o seu trabalho no sentido de "contribuir para a auto(trans)formação de todos e, consequentemente, para a transformação da sociedade" (HENZ, 2014, p. 51). Isso desafia o educador a atitudes críticas e o convívio com as incertezas, pois parte da pressuposição de que o professor é (re)construtor de conhecimentos, das ações, das reflexões, bem como um sujeito autor e provocador de mudanças. Freire (2015a) corrobora e aponta o direcionamento para a auto(trans)formação permanente do professor.

A melhora da qualidade da educação implica a formação permanente dos educadores. E a formação permanente se funda na prática de analisar a prática. É pensando sua prática, naturalmente com a presença de pessoal altamente qualificado, que é possível perceber embutida na prática uma teoria não percebida ainda, pouco percebida ou já percebida, mas pouco assumida (p. 84-85).

Ainda é importante destacarmos que o reflexo da auto(trans)formação permanente não é imediato, mas acontece ao longo dos estudos (iniciais e permanentes) e no exercício da profissão docente. Nesse sentido, as ações requerem ser mais amplas e, ao mesmo tempo, capazes de desenvolver um papel mais ativo do professor no planejamento, no desenvolvimento, na avaliação e na reformulação de estratégias e programas de pesquisa de intervenção educacional, de forma conjunta à comunidade (IMBERNÓN, 2011). Desse modo, possibilitam-se condições para o professor (re)pensar práticas pedagógicas amplas, diversificadas e inovadoras. Daí a importância de valorizar e compartilhar as diferentes experiências vivenciadas em cada momento do processo da aprendizagem do professor, ou seja, no seu desenvolvimento profissional. Para tanto, as escolas podem tornar-se lócus privilegiado, se conseguirem organizar tempos-espaços específicos para estudos e processos de ação-reflexão-ação com/entre todos os professores, propiciando condições e recursos para construir um distanciamento crítico- reflexivo, para "ad-mirar" e, talvez, mudar, as suas práticas com os estudantes.

\section{(In)Conclusões}

A importância dos momentos de ação-reflexão-ação, por meio da troca de experiências, da reflexão crítica sobre a prática e, consequentemente, o desenvolvimento de sujeitos reflexivos, conscientes, críticos, dialógicos, conhecedores de si mesmo, da sua história, da sua cultura, de seus conflitos, capazes de avaliar a sua ação, para transformá-la, 
contribuem para o fortalecimento da auto(trans)formação permanente, bem como com o desenvolvimento profissional docente. Tudo isso sempre em coautoria com os outros, por diferentes movimentos viabilizados pela (com)vivênvia dialógico-reflexiva e pelo (re)conhecimento de cada participante na sua outredade.

Com as respostas dos questionários e as narrativas emergidas nos encontros dos Círculos Dialógicos Investigativo-formativos, conseguimos evidenciar que a interação de formador-formando necessita ser de afinidade, de cooperação e de desenvolvimento auto(trans)formativo, pessoal e profissionalmente. O pibidiano desenvolve-se como indivíduo participativo, comunicativo e proativo em seu caminho de formação em diálogo com os outros sujeitos do processo educativo, formando-se e auto(trans)formando-se como pessoa e como profissional. Nessa perspectiva, faz-se necessário que, desde o início "do processo, vá ficando cada vez mais claro que, embora diferentes entre si, quem forma se forma e re-forma ao formar e quem é formado forma-se e forma ao ser formado" (FREIRE, 2011, p. 14). As reflexões sobre o processo de inserção na escola, realizadas por meio do PIBID foram intensas nos diferentes campi. Quando os coautores contavam sobre sua primeira experiência, ouvia-se o "riso" de muitos; os grupos demonstravam estar atentos e exercitavam a escuta sensível e o olhar aguçado aos "dizer a sua palavra" de cada participante, o que, segundo eles (participantes da pesquisa), contribuiu para a (re)construção e o fortalecimento da identidade do grupo. Conhecer a história de cada colega os fez reviver e reinterpretar emoções e acontecimentos, contribuindo para seu crescimento pessoal e profissional. Escutar os outros é um pouco escutar a si mesmo; a história deles faz reviver e (re)significar momentos da própria história e descobrir a importância dos mesmos para o nosso modo de exercer a profissão docente.

Nessa direção, entende-se que a vivência na formação inicial e no PIBID contribui para a "preparação e a iniciação ao processo identitário e de profissionalização dos profissionais de diferentes áreas" (PIMENTA; ANASTASIOU, 2002, p. 105). Isso indica que a auto(trans)formação permanente demanda uma constante conjuntura de estudo e de diálogos de socialização e ação-reflexão-ação; significa encontrar-se em permanentes movimentos reflexivos e em desenvolvimento pessoal e profissional, que se iniciam desde as primeiras vivências como alunos e têm prosseguimento no decurso das "experiências de vida e formação" (JOSSO, 2004), pelas quais vai constituindo a identidade e a profissão docente.

A pesquisa de doutorado, por meio dos Círculos Dialógicos Investigativo-formativos, faz-nos acreditar e afirmar que a escola é um lócus em que se efetivam as relações de auto(trans)formação permanente entre os bolsistas de iniciação à docência e os professores da Educação Básica. Essa relação oportuniza debates e reflexões que envolvem o conjunto escolar, com temáticas e projetos que abranjam o contexto e as necessidades de melhoria na práxis docente. A diversidade de atividades e de ações desenvolvidas pelos pibidianos, bem como o convívio e o (re)conhecimento do ambiente escolar pelos bolsistas de iniciação do PIBID oportunizam trocas de aprendizagens e conhecimentos que ocorrem durante as atividades organizadas, realizadas e compartilhadas com os estudantes em sala de aula. 
Ressaltamos, também, que o relacionamento, o exemplo, o comprometimento e a dialogicidade entre o licenciando e professor formador é muito enriquecedor para a auto(trans)formação permanente e o desenvolvimento profissional docente de ambos. No inacabamento e na abertura para os diferentes movimentos geradores de novas formas de sentir/pensar/agir como licenciandos e professores pibidianos, auto e interformativamente cada um vai se constituindo, por meio de um "caminhar para si" (JOSSO, 2010) com os outros, como pessoa e como profissional.

\section{Referências}

BRANDÃO, Carlos Rodrigues. O que é Método Paulo Freire. Editora Brasiliense. Coleção Primeiros Passos. 2013. 115 p. ISBN 85-11-01038-6.

CHIZZOTTI, Antonio. Pesquisa em Ciências Humanas e Sociais. São Paulo: Cortez, 2010.168 p. ISBN 9788524904448.

CHIZZOTTI, Antonio. Pesquisa qualitativa em ciências humanas e sociais. 6. ed. Petrópolis, RJ: Vozes, 2014. 144 p. ISBN 978-85-326-3390-3.

DAY, Christopher. Desenvolvimento profissional de professores: os desafios da aprendizagem permanente. Porto, Portugal: Porto Editora. 2001. 351 p. ISBN 9789720348074.

FIORI, Ernani Maria. Aprender a dizer sua palavra (Prefácio). In: FREIRE, Paulo. Pedagogia do Oprimido. Rio de Janeiro, RJ: Paz e Terra, 1987. 256 p. ISBN 978-8577531646.

FREIRE, Paulo. Educação e mudança. 1. ed. Rio de Janeiro, RJ: Paz e Terra, 1979. 112 p. 978-8577531707.

FREIRE, Paulo. Pedagogia do oprimido. 17. ed. Rio de Janeiro, RJ: Paz e Terra, 1987. 256 p. ISBN 978-8577531646.

FREIRE, Paulo. A importância do ato de ler - em três artigos que se completam. 51. ed. 2. reimp. Perdizes. São Paulo, SP: Cortez Editora, 2011. 102 p. (Coleção questões da nossa época; v.22). ISBN 978-85-249-1646-5.

FREIRE, Paulo. Professora sim, tia não: cartas a quem ousa ensinar. 1. ed. São Paulo, SP: Paz e Terra, 2013. 192 p. ISBN 978-8577532612.

FREIRE, Paulo. Educação como prática da liberdade. 33. ed. São Paulo, SP: Paz e Terra, 2014. 189 p. ISBN 978-85-7753-165-3.

FREIRE, Paulo. Pedagogia da Autonomia - saberes necessários a prática educativa. 24. ed. São Paulo, SP: Paz e Terra, 2015a. 144p. ISBN 978-85-7753-163-9.

FREIRE, Paulo. Política e Educação. Organização de Ana Maria Araújo Freire. 2. ed. São Paulo, SP: Paz e Terra, 2015b.144 p. ISBN 978-85-7753-291-9. 
FREITAS, Ana Lúcia Souza de. Conscientização. In: STRECK, Danilo; REDIN, Euclides; ZITKOSKI, Jaime José (Org.). Dicionário Paulo Freire. 2. ed. Belo Horizonte: Autentica, 2010. p. 88-89. 439 p. ISBN 978-85-7526-306-8.

GAMA, Renata Prenstteter. Desenvolvimento profissional com apoio de grupos colaborativos: o caso de professores de matemática em início de carreira. 2007. 240 f. Tese (Doutorado em Educação Matemática), Universidade Estadual de Campinas, Campinas, SP, 2007.

GARCIA, Carlos Marcelo. A Formação de Professores: Novas perspectivas baseadas na investigação sobre o pensamento do professor. In: Nóvoa, A (Org.). Os professores e sua formação. Lisboa, Portugal: Publicações Dom Quixote, 1992. p. 51-76. ISBN 972-20-10085 .

GARCIA, Carlos Marcelo. Formação de professores: para uma mudança educativa. Portugal, Porto: Porto Editora, 1999. 272 p. ISBN 978-972-0-34152-5

GIL, Antonio Carlos. Estudo de caso. São Paulo: Atlas, 2009. 168 p. ISBN 978-85-2245532-4.

HENZ, Celso Ilgo. Razão-emoção crítico-reflexiva: um desafio permanente na capacitação de professores. Porto Alegre, RS: UFRGS, 2003. Tese [Doutorado] - Universidade Federal do Rio Grande do Sul.

HENZ, Celso Ilgo. "Dialogus": Formação Permanente, Humanização e Cidadania. In: VI ENCONTRO INTERNACIONAL DE INVESTIGADORES DE POLÍTICAS EDUCATIVAS (VI EIIPE), HENZ, Celso Ilgo (Org.). - Santa Maria. Anais... Santa Maria, Universidade Federal de Santa Maria, Asociación de Universidades Grupo Montevideo, 2014a. p. 47-52.

HENZ, Celso Ilgo. Círculos, dialógicos investigativo-formativos: pesquisa-formação permanente de professores. In: SEMINÁRIO NACIONAL COM PAULO FREIRE, 8., Bento Gonçalves, Anais... Bento Gonçalves, RS. 2014b. p. 448-457. ISBN: 978-85-64961-06-7 . Ebook.

HENZ, Celso Ilgo Círculos Dialógicos Investigativo-Formativos e Auto(trans)formação Permanente de Professores. In: HENZ, Celso Ilgo; TONIOLO, Joze Medianeira dos Santos Andrade. (Orgs.). Dialogus: círculos dialógicos, humanização e auto(trans)formação de professores. São Leopoldo, RS: Editora Oikos. 2015. p. 17-28. 160 p. ISBN 978-85-7843554-7.

HENZ, Celso Ilgo; FREITAS, Larissa Martins. Círculos dialógicos investigativo-formativos: uma possibilidade de pesquisa entrelaçando os círculos de cultura freireanos e a pesquisaformação. In: Fórum de estudos e leituras de Paulo Freire - educar com seriedade sim, mas com alegria! as classes populares na educação pública, 17, Santa Maria. Anais... Santa Maria, RS.

IMBERNÓN, Francisco. Formação permanente do professorado: novas tendências. Tradução de Sandra Valenzuela. São Paulo: Cortez, 2009. 118 p. ISBN 978-85-249-1494-2. 
IMBERNÓN, Francisco. Formação continuada de professores. Porto Alegre: Artmed, 2010. 120p. ISBN 978-85-363-1986-5.

IMBERNÓN, Francisco. Formação docente e profissional formar-se para a mudança e a incerteza. São Paulo: Cortez. São Paulo, SP. 2011.127 p.ISBN 978-85-249-1630-4

ISAIA, S. M. A; BOLZAN, D. P. V.; (Org.). Trajetórias da docência: articulando estudos sobre os processos formativos e a aprendizagem de ser professor. In: Pedagogia universitária e desenvolvimento profissional docente. Porto Alegre: Ed.PUCRS: 2009. p. 121-143.248 p. ISBN 978857391125-1.

ISAIA, Silvia Maria de Aguiar. Verbetes. In: CUNHA, Maria Isabel da. ISAIA, Silvia Maria de Aguiar. Formação Docente e Educação Superior. In: MOROSINI, Marília Costa. (Org.) Enciclopédia de pedagogia universitária: glossário. Brasília: [s.n], 2006. p. 351-381. v.2.

JOSSO, Marie-Christine. Experiências de vida e formação. São Paulo, SP: Cortez, 2004. 288p. ISBN 9788524910074.

JOSSO, Marie-Christine. Caminhar para si. Tradução Albino Pozzer, revisão Maria Helena Menna Barreto Abrahão. Porto Alegre: Ed.PUCRS, 2010. 340 p. ISBN 857430980X

MARCELO, Carlos. A identidade docente. Revista Brasileira de Pesquisa sobre Formação Docente. Belo Horizonte, MG: v. 1, n. 1, p. 109-131, ago./dez. 2009. ISNN 2176-4360

NÓVOA, Antonio. (Org.). Formação de Professores e Profissão Docente. In: Os professores e a sua formação. Portugal: Porto, 1997. ISBN 972-20-1008-5.

NÓVOA, Antonio. Para uma formação de professores construída dentro da profissão. Revista de Educación. n. 350, dez. 2009, p. 203-218. Disponível em:

<http://www.mecd.gob.es/revista-de-educacion/numeros-revista-educacion/numerosanteriores/2009/re350.html>. Acesso em: 05 mar. 2017.

PIMENTA, Selma Garrido; ANASTASIOU, Léa das Graças Camargos. Docência no ensino superior. São Paulo: Cortez, 2002. 280 p. ISBN 9788524922145.

SANTOS, Lucíola Licínio de Castro Paixão. Problemas e alternativas no campo da formação de professores. Revista Brasileira de Estudos Pedagógicos, Brasília, DF: v. 72, n. 172, p. 318-334, set./dez. 1991. pp. 318-334. 225 p. ISSN 0034-7183.

STRECK, Danilo. Esperança. In: STRECK, Danilo; REDIN, Euclides; ZITKOSKI, Jaime José (Org.). Dicionário Paulo Freire. 2. ed. Belo Horizonte: Autentica, 2010. p. 161. 439 p. ISBN 978-85-7526-306-8.

ZITKOSKI, Jaime José. Diálogo/dialogicidade. In: STRECK, Danilo; REDIN, Euclides; ZITKOSKI, Jaime José (Org.). Dicionário Paulo Freire. 2. ed. Belo Horizonte: Autentica, 2010. p. 117-118. 439 p. ISBN 978-85-7526-306-8.

YIN, Robert K. Estudo de caso - planejamento e métodos. HERRERA, Cristhian Matheus. (Trad.), 5. ed. Porto Alegre, RS: Bookman, 2015. 209 p. ISBN 978-85-8260-231-7.21. 